\title{
化学师范生教师资格证国家考试现状调查及对策
}

黄静 ${ }^{*}$, 许燕李

福建师范大学化学与材料学院, 福州 350117

摘要: 通过问卷调查, 统计分析了X师范大学化学师范生教师资格证国家考试(简称 “国考”)的现状, 揭示了考试通 过率较低; 学生认识程度不足、备考方式单一; 课程学习与考试进度不匹配; 教学内容方法待更新; 教学实践训练 不足等存在的问题, 并从学校教师关注度、课程设置安排、教学内容方法、教学实践训练四个方面进行归因分析, 从而有针对性地提出引导化学师范生积极应对国考以及提升教师素养的对策。

关键词：化学师范生；教师资格证；国家考试；现状；对策

中图分类号: G64; O6

\section{Investigation about the Status of National Examination for Teacher Certificate of Pre-Service Chemistry Teachers and Its Countermeasures}

\author{
Jing Huang *, Yanli Xu \\ College of Chemistry and Materials, Fujian Normal University, Fuzhou 350117, China.
}

\begin{abstract}
This paper conducted a questionnaire survey to record the statistics and analyze the status quo of National Examination for Teacher Certificate among pre-service chemistry teachers in X Normal University. The results revealed a relatively low examination pass rate, insufficient knowledge depth among the pre-service teachers, and a highly uniform method of exam preparation. Moreover, the analysis also showed that the course completion was not in harmony with the tested content, the teaching content as well as methods require further revision, and the practical teaching training conducted was below par. Subsequently, regression analysis was conducted with respect to the level of attention put by the university teachers, the curriculum arrangement, the teaching content and methods, as well as practical teaching training, based on which result the targeted countermeasures were proposed. This study was aimed at guiding the pre-service chemistry teachers to actively face the national examination as well as improve their qualities as teachers-to-be.
\end{abstract}

Key Words: Pre-service chemistry teachers; Teacher certificate; National examination; Status; Countermeasures

从2015年开始, 全国实施新的中小学、幼儿园教师资格证考试制度, 即全国教师资格证统一考 试(以下简称为 “国考” )制度 ${ }^{[1]}$ 。此次改革最大的变化在于, 师范生将不再享有直接被认定教师资格 的 “特权” , 他们和非师范生一样, 想要做教师都必须参加国考, 通过后方可申请教师资格证。国 考对高师院校师资培养提出了新的要求, 迫使学校不得不重新审视其课程设置是否合理、师范生从 教意愿是否强烈, 教育实习开展是否有效等一系列问题并进行相应的改革与实践 ${ }^{[2]}$ 。确保毕业生顺

收稿: 2020-08-24; 录用: 2020-09-07; 网络发表: 2020-09-25

“通讯作者, Email: huang198731@163.com

基金资助：福建师范大学本科教学改革研究项目(I201803010); 福建师范大学 2020 年课程思政示范课程项目(K202001019) 
利取得教师从业资格的同时, 更加适应未来教师岗位对专业能力的要求。

国考实行以后, 学者们对其研究主要集中在两个方面, 一是对国考制度本身的评价与审思; 二 是基于国考对教师教育专业发展改革的思考：包括探索课程体系的构建、变革人才培养模式等等。 但从师范生角度探索国考现状以及培养存在问题的相关研究还比较少。在国考背景下, 作为直接关 系者的师范生对制度的实施持何种态度? 他们是如何备考的, 现行的培养模式成效如何? 这一系列 问题都亟待做出一些回应, 同时也是高师院校师资培养变革的重要依据。本研究借助问卷调查获得 了化学师范生教师资格证国考现状以及对现有培养模式看法的基本数据。基于调查结果揭示化学师 范生国考及培养过程中存在的问题, 并进行归因分析, 从而有针对性地提出对策, 旨在为师范生更 好地应对国考、提升专业素养以及化学教育专业建设提供理论参考。

\section{1 研究设计}

\section{1 研究对象}

本次选取的研究对象为X师范大学2015级与2016级化学师范生, 共 164 人。调查施测时, 所有人 均修习完师范生规定课程。他们对参与国考的过程以及专业课程学习情况有比较全面的认识, 同时 能够客观地进行自我评估。本次调查一共发放问卷164份, 回收问卷164份, 有效问卷160份, 测试时 间为2020年3月。此外, 随机抽取20名师范生作为访谈对象进行访谈。

\section{2 研究方法}

本研究主要借助问卷调查法了解化学师范生国考及培养现状, 揭示存在的问题。笔者采用自编 的 “化学师范生教师资格证国家考试现状调查” 问卷进行调查分析, 问卷包含四个方面的考查内容, 即师范生对国考政策的态度、了解程度、备考情况以及国考背景下师范生对现有培养模式的基本看 法。本实证研究兼用访谈法, 访谈内容主要围绕问卷考查内容进行更深层面的信息搜集, 从而对问 题进行归因并提出相关建议。

\section{2 研究与结果分析}

\section{1 化学师范生国考概况}

笔者通过问卷调查, 了解化学师范生国考通过率、从教意愿以及他们对国考相关政策的认知态 度。数据统计如表 1 、表2所示。

表1 化学师范生国考通过率的统计分析

\begin{tabular}{|c|c|c|c|c|c|c|}
\hline 报考次数 & $\begin{array}{c}\text { 综合素质 } \\
\text { 报考人数/通过人 } \\
\text { 数/通过率 }\end{array}$ & $\begin{array}{c}\text { 教育知识与能力 } \\
\text { 报考人数/通过人数/ } \\
\text { 通过率 }\end{array}$ & $\begin{array}{c}\text { 化学学科知识与 } \\
\text { 教学能力 } \\
\text { 报考人数/通过人 } \\
\text { 数/通过率 }\end{array}$ & $\begin{array}{c}\text { 笔试(三科) } \\
\text { 报考人数/通过 } \\
\text { 人数/通过率 }\end{array}$ & $\begin{array}{c}\text { 面试 } \\
\text { 报考人数/通过人数/ } \\
\text { 通过率 }\end{array}$ & $\begin{array}{c}\text { 国考通过率 } \\
\text { (通过人数占 } 2016 \text { 级师 } \\
\text { 范生总人数的百分比) }\end{array}$ \\
\hline 第一次 & $71 / 50 / 70.42 \%$ & $71 / 56 / 78.87 \%$ & $71 / 51 / 71.83 \%$ & $71 / 30 / 42.25 \%$ & $23 / 21 / 91.30 \%$ & $26.25 \%$ \\
\hline 第二次 & $25 / 22 / 88.00 \%$ & $20 / 14 / 70.00 \%$ & $26 / 22 / 84.62 \%$ & $41 / 38 / 92.68 \%$ & $42 / 41 / 97.62 \%$ & $77.50 \%$ \\
\hline 第三次 & $6 / 2 / 33.33 \%$ & $6 / 1 / 16.67 \%$ & $7 / 6 / 85.71 \%$ & $12 / 8 / 6.67 \%$ & & \\
\hline
\end{tabular}

\subsection{1 考试通过率}

截止2020年3月, 2016级化学师范生可以参加3次国考笔试、2次面试。通过表1, 我们看到首次 国考通过率仅为 $26.25 \%$ 。第二次考试后通过率为 $77.5 \%$ 。截止统计之时, 80 名化学师范生, 62 人已通 过国考, 6 人笔试通过待面试, 11 人笔试还未通过, 1 人从未报名。总体而言, 考试通过率偏低, 在 临近毕业时还有 $22.5 \%$ 的师范生未获取教师从业资格。取得教师资格证是入职教师职业最基本的门 槛, 若不能尽快通过国考, 势必会导致师范生产生焦虑情绪, 对其日常学习和未来择业带来消极影响。 


\subsection{2 师范生从教意愿以及对国考政策的态度}

表2显示, 国考背景下绝大部分师范生从教意愿强, 没有因为政策变化受到消极影响。同时超过 半数的师范生对国考政策持相对认可的态度, 认同国考改革给师范生带来的机遇与挑战。

\section{表2 化学师范生从教意愿以及对国考的态度}

\begin{tabular}{llc}
\hline \multicolumn{1}{c}{ 题目 } & \multicolumn{1}{c}{ 选项 } & 选中的百分比 \\
\hline 第1题: 在 “国考” 背景下, & A. 十分愿意 & $27.5 \%$ \\
你是否还愿意长期认真的从事 & B. 愿意 & $60 \%$ \\
教师职业? & C. 不愿意 & $12.5 \%$ \\
第2题: 对于师范生也需要参 & A. 能提高师范生的危机感 & $61.25 \%$ \\
加教师资格证考试, 你的看法 & B. 考试人数增加, 考试难度加大 & $33.75 \%$ \\
是(多选题) & C. 可以增加师范生毕业的含金量, 促进师范院校学生培养质量的提升 & $57.5 \%$ \\
& D. 不能提高毕业生的含金量, 反而会导致大学课程的学习质量下降 & $15 \%$ \\
& E. 其他 & $3.75 \%$ \\
\hline
\end{tabular}

\section{2 化学师范生国考存在问题的分析}

\subsection{1 对教师资格证制度了解程度不足, 认识渠道有限}

表3呈现了化学师范生对教师资格证各科目考试大纲、题型内容、面试流程等信息的了解程度以 及认识渠道。通过数据, 我们了解到部分学生知道要参加考试, 但对于怎么考、考什么的问题没有 很好的认知, 了解程度不足, 导致备考缺乏针对性。同时, 师范生对国考相关资讯的了解方式比较 单一有限, 备考信息来源主要依靠互联网, 其他途径较少。而互联网上的信息庞杂、琐碎, 需要师 范生自行鉴别篮选、整理归纳。

\section{表3 化学师范生对国考相关信息的了解程度以及了解途径统计分析}

\begin{tabular}{lccc}
\hline 题目/选项 & $\begin{array}{c}\text { 第3题: 你备考时对笔试科 } \\
\text { 目的考试大纲了解程度是 }\end{array}$ & $\begin{array}{c}\text { 第4题: 你备考时对笔试题 } \\
\text { 型、内容了解程度是 }\end{array}$ & $\begin{array}{c}\text { 第5题: 你备考时对面试流程 } \\
\text { 的了解程度是 }\end{array}$ \\
\hline A. 非常了解 & $11.25 \%$ & $20 \%$ & $21.25 \%$ \\
B. 比较了解 & $41.25 \%$ & $47.5 \%$ & $46.25 \%$ \\
C. 基本了解 & $36.25 \%$ & $28.75 \%$ & $21.25 \%$ \\
D. 不太了解 & $11.25 \%$ & $3.75 \%$ & $11.25 \%$ \\
E. 完全不了解 & $0 \%$ & $0 \%$ & $0 \%$ \\
& & 第6题: 你主要通过哪种途径了解国考相关资讯? & \\
A. 学校 & & $13.75 \%$ & \\
B. 老师 & & $2.5 \%$ & \\
C. 同学 & & $13.75 \%$ & \\
D. 互联网 & & $68.75 \%$ & \\
E. 培训机构 & & $1.25 \%$ & \\
\hline
\end{tabular}

\subsection{2 备考方式单一, 仓促应考, 学习缺乏积极性}

表4呈现了化学师范生备考时间、方式以及备考过程中存在的困难等相关信息。数据显示化学师 范生备考时间较短, 且大部分师范生备考方式单一。通过访谈得知学校极少为学生提供相应的培训 讲座, 而教育机构培训费用高, 因此 $91.25 \%$ 的师范生选择自行看书复习备考。但在复习过程中, 近 半数的学生没有制定科学系统的复习计划, 学习缺乏积极性, 加上笔试知识点庞杂, 面试前没有足 够的教学实践训练, 专业技能不熟悉而感觉复习压力大, 备考艰难。 
大学 化 学 Univ. Chem. 2021, 36 (6), 2008053 (4 of 7)

表4 化学师范生国考备考情况分析

\begin{tabular}{|c|c|c|}
\hline 题目 & 选项 & 选中的百分比 \\
\hline \multirow[t]{4}{*}{ 第7题：你备考时间大约多长? } & A. 少于三个月 & $83.75 \%$ \\
\hline & B. 三个月 & $13.75 \%$ \\
\hline & C. 三个月到六个月 & $2.5 \%$ \\
\hline & D. 六个月以上 & 0 \\
\hline \multirow{5}{*}{$\begin{array}{c}\text { 第 } 8 \text { 题：你是如何进行国考备考的？ } \\
\text { (多选题) }\end{array}$} & A. 参加校外培训机构 & $5 \%$ \\
\hline & B. 自行看书备考复习 & $91.25 \%$ \\
\hline & C. 学校组织相关培训 & $1.25 \%$ \\
\hline & D. 观看网络培训课程 & $2.5 \%$ \\
\hline & E. 其他 & 0 \\
\hline \multirow[t]{4}{*}{ 第9题：笔试备考过程中感觉困难的主要原因是 } & A. 记忆能力差, 知识点记不住 & $42.5 \%$ \\
\hline & B. 很多内容在大学中没有接触过, 感到陌生 & $8.75 \%$ \\
\hline & C. 没有合理的制定复习计划, 时间紧迫 & $46.25 \%$ \\
\hline & D. 其他 & $2.5 \%$ \\
\hline \multirow[t]{3}{*}{ 第10题: 面试备考过程中感觉困难的主要原因是 } & A. 基础教学技能不熟练 & $15 \%$ \\
\hline & B. 平时没有足够的教学实践训练 & $80 \%$ \\
\hline & C. 其他 & $5 \%$ \\
\hline
\end{tabular}

\subsection{3 课程学习与考试安排进度不匹配, 教学内容与方法待优化}

表 5 呈现了师范生对现行课程设置及教学方法的看法。73.75\%的师范生认为部分课程安排与考 试时间不匹配。 $68.75 \%$ 的师范生指出国考中部分考试内容在现有教师教育课程体系中未涉及, 需要 师范生自行寻找资料复习。此外, 53.75\%的师范生表明期望老师采用案例分析的教学方式, 对学习 帮助较大, 学习效果比较理想, 而在访谈过程中他们表示目前有许多教师在课堂教学中仍以理论讲 授为主。

表5 化学师范生对现行课程设置及教学方法的看法

\begin{tabular}{llc}
\hline \multicolumn{1}{c}{ 题目 } & \multicolumn{1}{c}{ 选项 } & 选中的百分比 \\
\hline 第13题: 你认为当前课程设置主要存在 & A. 部分课程安排与考试时间不匹配 & $73.75 \%$ \\
什么问题? (多选题) & B. 部分国考内容在课程中未涉及 & $68.75 \%$ \\
& C. 教师教育课程偏少 & $62.5 \%$ \\
& D. 教师技能实践训练不足 & $72.5 \%$ \\
& E. 其他 & 0 \\
第15题: 你认为教师采用哪种教学方法 & A. 讲授为主的教学方式 \\
对你帮助较大? & B. 问题启发思考讨论的教学方式 & $12.5 \%$ \\
& C. 案例列举分析的教学方式 & $28.75 \%$ \\
& D. 学生分组汇报的教学方式 & $53.75 \%$ \\
& & $5 \%$ \\
\hline
\end{tabular}

\subsection{4 教学技能训练不足, 教学实践能力亟需提升}

通过调查, 笔者了解到师范生普遍认为自身教学实践能力有待提升, 希望获得更多的教学技能 训练与实践机会: 表4、表 5 数据显示, $80 \%$ 的化学师范生在国考面试备考过程中主要困难来自平时 没有足够的实践训练; $72.5 \%$ 的师范生认为现有课程对教师技能训练不足, 并在访谈中表示国考后最 希望提升的项目是教学实践能力; 表6呈现师范生对教育实习的看法, 数据表明, $86.25 \%$ 的师范生认 
可教育实习对教学实践能力提升的重要作用, 但近半数的师范生希望实习基地能注重规范培养过程 并给予实习生更加细致的指导。

表6 化学师范生对教育实习的看法

\begin{tabular}{clc}
\hline \multicolumn{1}{c}{ 题目 } & \multicolumn{1}{c}{ 选项 } & 选中的百分比 \\
\hline 第17题: 通过教育实习, 你获取了 & A. 非常符合 & $26.25 \%$ \\
许多知识, 提高了教学实践能力。 & B. 比较符合 & $60 \%$ \\
& C. 一般 & $12.5 \%$ \\
& D. 比较不符合 & $1.25 \%$ \\
& E. 非常不符合 & 0 \\
第18题: 你认为教育实习可以从以 & A. 适当延长教育实习时间, 提供更多实习机会 & $33.75 \%$ \\
下哪些方面进行优化? (多选题) & B. 实习基地制定合理的培养计划, 规范培养过程 & $48.75 \%$ \\
& C. 实习基地教师给予实习生更细致的指导 & $46.25 \%$ \\
& D. 给予师范生更为科学的实习成绩评定 & $31.25 \%$ \\
& E. 其他 & $1.25 \%$ \\
\hline
\end{tabular}

\section{3 化学师范生国考及培养过程存在问题的归因分析}

\section{1 学校、教师对国考关注不够, 提供的资源信息有限, 忽视对学生的备考指导}

近几年随着社会发展, 地方高师院校尤其是省属重点师范院校逐步向综合性大学拓展。在综合 发展的目标导向下, 学校对教师资格证考试改革动态并没有给予足够的关注, 没有为学生了解国考 搭建专门的信息平台或提供资源指导其备考。同时教师教育类课程的授课教师对国考的了解也不够 深入, 他们在日常教学过程中很少提及国考相关资讯与内容。因此大多数师范生是通过网络、同学 泛泛了解考试的科目、形式, 但对考纲、核心考点、题型等具体的细节及要求知之甚少。其中许多 学生并没有系统地制定计划备考, 而是仓促应考, 导致考试结果不理想。

\section{2 课程设置 “师范性” 不突出, 课程安排不够合理}

通过对X师范大学2016级化学专业培养方案中课程结构表进行统计分析, 针对化学师范生培养, 专业基础和主干课程共计 67 学分, 占课程总学分比例 $42.7 \%$; 教师教育类课程学分为 16 , 占课程总学 分比例为 $10.06 \%$, 其中必修课程学分为 12 , 选修课程学分为 4 , 虽然满足师范专业认证的要求, 但相 较其他几所师范院校, 该校学科专业课程比例较高, 教师教育类课程比例偏低, 具体数据见表 7 。这 样的课程结构 “师范性” 不突出, 不能展现师范专业特色, 甚至影响师范生的专业认同感。此外, 根据教学计划表与访谈调查得知, 与化学学科知识与教学能力考试相关的课程都在大三才开设: 化 学教学论、中学化学实验与教学研究在第 5 学期开设; 化学教学设计与化学微格教学在第 6 学期开设。 这导致师范生刚开始接触化学课程与教学的相关知识就需要参加笔试, 首次通过笔试的学生还未经 过微格教学系统的技能训练就面临面试考核。在国考背景下, 这样的课程安排不够合理, 给学生备 考造成了较大压力与困难。

表7＼cjkstart各师范院校化学专业教师教育类课程设置比例对比分析

\begin{tabular}{cccc}
\hline 院校名称 & 总学分 & $\begin{array}{c}\text { 教师教育课程 } \\
\text { 所占学分 }\end{array}$ & $\begin{array}{c}\text { 教师教育课程 } \\
\text { 所占学分比例 }\end{array}$ \\
\hline X师范大学 & 156 & 16 & $10.3 \%$ \\
北京师范大学 & 155 & 19 & $12.3 \%$ \\
华东师范大学 & 155 & 23 & $14.7 \%$ \\
华中师范大学 & 130 & 16 & $12.3 \%$ \\
\hline
\end{tabular}




\section{3 教师教育类课程未对接国考改革进行调整, 教学内容陈旧, 教学方法单一}

教师资格证考试改革后, 考试范围更广, 考查更加灵活。但该校化学专业培养方案中教师教育 类课程未增设与国考内容相关的新课程, 依旧保持教育学基础、心理学基础、发展与教育心理学、 现代教育技术、化学教学论、化学教学设计、中学化学实验与教学研究这7门必修课程。经过访谈调 查, 师范生表示这些课程的教学内容没有包含教育法律法规、教师职业道德规范、文化素养等国考 考试大纲要求的模块, 而这部分内容需要师范生在课余时间自学。此外, 由于课时数有限, 知识容 量大等因素, 部分课程的教学过程局限于教师理论讲授, 教与学的方式单一, 学生缺乏深度思考, 不仅难以消化理解相关概念的内涵, 还很难将所学的教学理论灵活运用在实践教学中。

\section{4 课程教学过程重理论轻实践, 教学实践训练不足, 实习过程监管不到位}

该校化学师范生教师教育类课程所占比重较小, 而在这些课程中, 许多教师专注理论知识的讲 解, 时常忽略对学生灵活运用理论知识以及实践能力的培养。师范生教学技能训练主要依靠实践课 程: 其中微格教学 32 课时, 教育见习 1 周, 穿插在微格教学课程中, 教育实习 2 个月。微格教学课时 数偏少, 学生人数多, 教师无法引导每个学生完整地进行各项核心教学技能训练以及各种课型的模 拟试讲。教育见习、教育实习时间比较短, 且部分实习基地对实习生的管理较松散, 没有对其进行 有效的规范指导。学院指导教师每人负责 2-3个实习队, 每个实习队十几名学生, 且各个实习学校距 离较远, 指导教师没有时间深入课堂现场听课指导。实习结束后对师范生教学实践能力的考核又缺 乏具体、可测量的评价标准。因此, 仅通过理论知识的讲授和有限的实践训练, 师范生的教师素养 较难获得有效提升。

\section{4 引导化学师范生积极应对国考以及提升教师素养的对策}

\section{1 加强学校对国考改革的关注, 构建有效渠道, 引导师范生积极备考}

高师院校不能放弃自己的主要阵地, 应该把培养优秀人民教师的任务作为自己的存量, 在这个 基础上考虑发展增量 ${ }^{[3]}$ 。国考最终目的在于培养一支优秀的教师队伍以适应社会发展对于师资力量 的需要。作为师范生, 通过国考取得教师资格证, 是最基本的要求 ${ }^{[4]}$ 。因此, 从学校的角度出发, 应 加强对国考的重视程度, 积极构建师范生了解国考相关信息的渠道。比如从学生入学开始, 通过开 会或者报告的形式, 使学生了解国考制度, 明确国考的目的和意义, 加强师范生对国考的重视程 度 ${ }^{[5]}$ 。学校还以国考为主题注册公众号, 向学生定期发布国考信息动态与备考指南, 通过留言交流 互动, 了解师范生学习备考的需求, 进而根据多数师范生的需求开设国考专题讲座, 让他们深入了 解国考具体考什么、应该怎么考, 引导其积极应对、科学备考。

\section{2 调整课程设置, 完善教学内容, 精准对接国考改革}

针对教师资格证制度的改革, 高师院校需要调整师范生课程设置, 丰富课程内容, 从师范生的 实际专业需求出发, 探索更加规范化的课程设置方案, 为学生考取教师资格证和就业奠定基础 ${ }^{[6]}$ 。 首先, 在教师教育综合理论课程的设置方面, 仅将视线聚焦传统教育学、心理学两方面的课程是不 够的, 根据教师教育课程标准以及国考各科目考试大纲的具体要求, 应适当增加教师教育类课程的 比重和课程门类, 并有效整合相关教学内容。该校在化学专业原有课程开设的基础上可考虑增设教 师职业道德与专业发展、教育政策与法规、班主任及班级管理等必修课程以及中学化学教学案例赏 析与研究、国内外中学化学教育改革动态等选修课程, 使化学教师教育类课程更加完善; 适当降低 化学学科课程比重, 删减现行略显繁杂且与培养优秀中学化学教师关联度不高的课程。此外, 为了 建立师范生专业认同感并保证学生在大三参加考试时已完成大部分教师教育类课程的学习, 应在大 一、大二学年就合理安排开设教师教育类理论课程, 在大三开设实践训练类课程并尝试将教育见习 贯穿于大一、大二、大三的教育理论学习中, 增加师范生对一线化学教学实际情况了解的同时引导 其将所学理论运用于实际, 加深对理论知识的理解。此外, 授课教师应加强对国考信息的关注, 基 于课程目标及国考的要求, 在教学设计过程中新增或强化考试核心内容。 


\section{3 改进教学方法, 构建科学的考核模式, 促进师范生积极高效学习}

教师教育类课程的教学, 教师可根据实际情况尝试理论学习结合案例观摩与实践训练的教学方 法: 理论学习环节以教师讲授为主, 学生参与讨论; 实践训练环节以学生亲身实践为主, 师生共同 点评。理论学习和实践训练环节的过程, 均有效结合案例观摩研讨 ${ }^{[7]}$ 。师生借助案例的 “准情境” 进 行交流讨论, 促进学生了解教学基本理论和方法并学会灵活运用相关理论知识 ${ }^{[8]}$ 。同时为了解决理 论课程课时不足, 无法有效展开课堂讨论的问题, 教师可尝试拓展课程教学形式, 建设与面授相结 合的网络课程, 线上线下联动教学, 最大限度地拓展学生学习。通过线上发布相关课程资源, 引导 学生自主学习形成初步认识及产生问题。线下现场教学即有较充裕的时间聚焦 “线上学习” 产生的 问题进行解惑式探讨和必要的实践训练。此外, 在优化教学方法的同时要探索建立科学的课程考核 模式, 比如在理论课程考核中既有过程性考核又有终结性考核, 实践课程中建立具体的、可测量、 可操作的评价标准, 这样有利于实现教、学、评一体化, 达到预设的教学目标。

\section{4 优化微格教学训练, 规范教育实习过程, 丰富日常培训形式, 提高教师教育素养}

为了提升师范生教学技能, 应该适当增加化学微格教学的课时数, 重视微格教学日常训练过程 的优化, 还可在微格教学课程中设置国考面试模拟演练模块, 对面试各环节进行有针对性的操作训 练。除了微格教学, 针对教育实习开展, 学院指导教师应事先与各实习基地进行细致沟通, 结合各 基地校情校况确定具体的实习方案。实习过程通过跟踪调查, 了解实习基地与师范生是否按照方案 的要求和标准开展工作, 并及时进行反馈、干预与调整。除了定期前往实习基地进行听评课, 协助 做好指导和管理工作外, 指导教师还需要定期通过视频会议、远程批改教案、观看学生教学录像等 方式加强对师范生的指导, 并做好指导工作记录, 借此形成对每位实习生的过程性评价资料, 与实 习基地提供的实习鉴定共同作为实习成绩考核依据, 公正科学地评价实习生, 促进实习生的发展。 此外, 学校还可通过开展师范生教学技能大赛, 以赛促学 ${ }^{[9]}$ 。同时邀请优秀的中学化学教师走进大 学课堂, 合作开展化学师范专业课程的第一课堂教学并指导教学竞赛活动、国考面试演练或开设专 题讲座分享教学成长历程与经验体会。通过这些方式丰富师范生日常教学实践能力训练形式, 提高 其教师素养。

\section{参 考 文 献}

[1] 寒世琼, 苒隆锋. 教育科学, 2017, No. 5, 52 .

[2] 张翠华, 郭琳琳. 沧州师范学院学报, 2018, No. 1, 86 .

[3] 韩震. 中国高等教育, 2006, No. 20, 24.

[4] 吴少怀. 教师资格证国考背景下的英语师范生培养研究——Y大学为例. 锦州: 渤海大学, 2019.

[5] 尹杉杉. 教师资格国考制度对江苏省体育教育专业学生的影响研究. 南京: 南京师范大学, 2018.

[6] 方璐, 毕建洪. 合肥师范学院学报, 2015, 33 (3), 102.

[7] 毕华林, 姜言霞, 元英丽. 化学教育, 2015, No. 16, 44.

[8] 王少卿. 化学教育(中英文), 2018, No. 6, 45 .

[9] 朱山立, 梁荣波, 张凌, 张翼然. 中国医学教育技术, 2010, No. 6, 576 . 